\title{
Determinação de mercúrio em águas sanitárias comercializadas em região do sudeste do Brasil
}

\author{
Determination of mercury content in bleaches sold in southeastern Brazil
}

\author{
Odair Zenebon*, Franca Durante de Maio*, Alice M. Sakuma*, Eliani Rosa*
}

\begin{abstract}
ZENEBON, O. et al. Determinação de mercúrio em águas sanitárias comercializadas em região do sudeste do Brasil. Rev. Saúlde Pública, 28: 127-30, 1994. Para determinação de mercúrio presente como contaminante nas águas sanitárias usadas para desinfecção de água e alimentos, foi proposto um tratamento de amostra com ácido clorídrico para eliminação do cloro. A técnica de espectrofotometria de absorção atômica com gerador de vapor utilizada para quantificação do mercúrio a prescntou uma recuperação de $103 \%$. Foram analisadas 69 amostras de águas sanitárias de 35 diferentes marcas, comercializadas no Estado de São Paulo. Os valores obtictos para a mediana e nonagésimo percentil foram respectivamente: 15 e 67 ug/L. Pelas concentrações de mercúrio encontradas nas águas sanitárias, verificou-se que, usanclo as quantidades rccomencladas para descontaminar água, frutas e hortaliças, o mercúrio residual não apresenta riscos à saúde, situando-se dentro dos valores estabelecidos pela legislação em vigor.
\end{abstract}

Descritores: Mercúrio, análise. Espectrofotometria de absorção atômica. Desinfetantes, análise.

\section{Introdução}

O cloro tem amplo uso como desinfetante químico para água de abastecimento público, onde a sua ação contínua tem a finalidade de assegurar a eliminação de patógenos responsáveis por toxinfecções, tais como: os responsáveis pela cólera, desinteria, febre tifóide, hepatite e outras, prevenindo epidemias que poderiam ser ocasionadas através da veiculação hídrica 6 . O Ministério da Saúde e as Secretarias de Saúde dos vários Estados brasilciros recomendam, pela simplicidade, baixo custo e eficácia, a utilização de soluções de hipoclorito para a desinfecção de água em regiões onde não existe saneamento básico, como medida preventiva no combate a essas doenças.

Das soluções de cloro, as mais conhecidas são as águas sanitárias comumente denominadas águas de lavadeira. Estes produtos disponiveis no comércio nada mais são que soluções diluídas de hipoclorito de sódio. A legislação em vigor estabelece um valor mínimo de $2,0 \%$ e máximo de $2,5 \%$ em cloro ativo nessas soluções 5 .

Seção de Equipamentos Especializados do Instituto Adolfo Lutz - São Paulo, SP - Brasil

Separatas/ Reprints: O. Zenebon - Av. Dr. Arnaldo, 355 01246-902 - São Paulo, SP - Brasil

Ediçĩo subvencionada pela FAPESP. Processo 94/0500-0
As soluções concentradas de hipoclorito de sódio são preparadas pelo borbulhamento de cloro gasoso em solução alcalina. A maior parte das indústrias de cloro utiliza o processo da eletrólise de solução de cloreto de sódio, empregando catodo de mercúrio clementar. Dependendo clas condições técnicas durante sua preparação, o cloro podcrá estar contaminado com mercúrio.

O mercúrio é um contaminante metálico que apresenta elevada toxicidacle devido aos efeitos acumulativos no organismo humano ${ }^{8}$.

Os métodos mais utilizados para determinar mercúrio baseiam-se em espectrofotometria na região do visível, através de reações colorimétricas, e em espectrofotometria de absorção atômica sem chama?. Em ambas as técnicas, há necessidade da eliminação do cloro das amostras a serem analisadas. Os métodos colorimétricos fundamentam-se na medida do complexo colorido entre o mercúrio e a ditizona em meio áciclo ${ }^{1}$.

Com o advento da cólera no Brasil e com as recomendações das autoridades do setor saúde, o uso das águas sanitárias atingiu grande importância na desinfecção não só da água, mas tambćm dos alimentos ingeridos crus, originando preocupação com a qualidade desses produtos com rclação à contaminação por mercúrio. Fundamentados na necessidade de controlar as águas sanitárias, no presente trabalho propõe-se 
metodologia adequada para tratamento da amostra para verificar os níveis de mercúrio nas águas sanitárias comercializadas no Estado de São Paulo, usando o método da cspectrolotometria de absorção atômica sem chama com gcrador de vapor.

\section{Material e Método}

\section{Material}

Foram usados os seguintes reagentes:

- Solução de ácido cloridrico 1:1-O ácido clorídrico isento de mercúrio foi diluído com água destilada e deionizada.

- Solução padrão estoque de mercúrio $1.000 \mathrm{mg} / \mathrm{L}-1.080 \mathrm{~g}$ de óxido de mercúrio (II) p.a. foram dissolvidos num mínimo volume de $\mathrm{HCl} 1: 1$ e o volume completado a $1.000 \mathrm{~mL}$ com $\mathrm{HCl} 1 \mathrm{M}$.

- Solução padrão intermediária de mercúrio - $25 \mathrm{mg} / \mathrm{L}$ em $\mathrm{HCl} 1 \mathrm{M}$, preparada mensalmente.

- Solução padrão de trabalho de mercúrio $20 \mu \mathrm{g} / \mathrm{L} \mathrm{em} \mathrm{HCl} 1 \mathrm{M}$, preparada no momento de usar.

- Solução de cloreto estanoso $20 \% \mathrm{p} / \mathrm{v} \cdot 20 \mathrm{~g}$ de $\mathrm{SnCl}_{2}$ p.a. dissolvidos em $20 \mathrm{~mL}$ de $\mathrm{HCl}$ $1: 1$, foram aquecidos até complcta dissolução e o volume completado a $100 \mathrm{~mL}$ com água.

- Tiras de papel indicador amido-iodetado

- Carvão ativo - 18 - 35 mesh

- Perclorato de magnésio granulado p.a.

- Lã de vidro

- Sílica com indicador de umidade

Todas as vidrarias, previamente lavadas com água e sabão e enxaguadas, foram descontaminadas, usando solução de ácido nítrico a $20 \%$ durante uma noite, e enxaguadas várias vezes com água destilada e desmineralizada.

O aparelho usado foi o espectrofotômetro de absorção atômica modelo $1.100 \mathrm{~B}$, marca Perkin-Elmer, com lâmpada de mercúrio e equipado com gerador de vapor.
Foram analisadas 69 amostras de água sanitária, de 35 difcrentes marcas, comercializadas no Estado de São Paulo, a fim de se determinar o tcor de mercúrio.

\section{Método}

A $1,0 \mathrm{~mL}$ da amostra pipelado $\mathrm{cm}$ frasco tipo $\mathrm{DBO}^{*}$, foram adicionados $5 \mathrm{~mL}$ de solução de ácido clorídrico. A mistura foi mantida em banho-maria a $60^{\circ} \mathrm{C}$ durante aproximadamente uma hora, agitando o frasco para agilizar a climinação do cloro. Foi feito o leste com papel amido-iodetado para verificar se todo cloro foi climinado; caso contrário, o aquecimento devia ser manticlo até a sua completa climinação. $\Lambda$ pós resfriamento, foi efetuada a leitura no espectrofotômetro de absorção atômica. Procedimento idêntico foi efetuado com o branco preparado com todos os reagentes usados.

As determinações de mercúrio foram feitas de acordo com o método de Hatch e $\mathrm{Ott}^{7}$.

No frasco, contendo a amostra, foi colocado água até cobrir o borbulhador do aparelho gerador de vapor de mercúrio. Foi adicionado $1,0 \mathrm{~mL}$ de solução de cloreto estanoso e, após 20 segundos, foi efetuada a leitura no espectrofotômetro de absorção atômica. Para o cálculo da concentração de mercúrio na amostra foi utilizada a curva analítica.

Em fiascos DBO, foram pipetadas alíquotas de 0,$5 ; 1,0 ; 2,0 ; 3,0$ e $4,0 \mathrm{~mL}$ da solução padrão de tuabalho. Após a adição de $5 \mathrm{~mL}$ de solução de ácido clorídrico, $\mathrm{cm}$ cada um dos frascos, foi efetuado o mesmo procedimento de leitura das amostras. Foi cstabelecida curva de absorvancia em função da concentração. Esta curva deve ser refeita todas as vezes que o aparclho for desligado.

\section{Resultados e Discussão}

\section{Teste de recuperação do método}

Para garantir a confiabilidade analítica do método proposto foi utilizada a adição de pa-

- Demanda bioquínica de oxigênio. 
Tabela 1. Teste de recuperação do mercúrio em Água sanitária*

\begin{tabular}{cccc}
\hline $\begin{array}{c}\text { Concentração de Hg na } \\
\text { amostra }(\mu \mathrm{g} / \mathrm{L})\end{array}$ & $\begin{array}{c}\mathrm{Hg} \text { adicionado } \\
(\mu \mathrm{g} / \mathrm{L})\end{array}$ & $\begin{array}{c}\text { Total de } \mathrm{Hg} \text { encontrado } \\
(\mu \mathrm{g} / \mathrm{L})\end{array}$ & $\%$ recuperação do Hg \\
\hline 39 & 20,0 & 62 & $107 \%$ \\
39 & 40,0 & 80 & $103 \%$ \\
39 & 60,0 & 100 & $103 \%$ \\
\hline
\end{tabular}

- Cada resultado da Tabela acima refere-se à média de três determinações.

drão, em razão da inexistĉncia de padrões de referência em nivel internacional.

A recuperação do mercúrio foi determinada pela adição de volumes adequados da solução padrão de trabalho a $1,0 \mathrm{~mL}$ da amostra contendo $39 \mu \mathrm{g} / \mathrm{L}$ de mercúrio. Essas amostras foram tratadas usando o mesmo procedimento do método proposto. Os resultados obtidos estão na Tabela 1 .

\section{Análise das amostras}

Os resultados das determinações de $\mathrm{Hg}$ nas amostras de água sanitária encontram-se na Tabela 2 .

Tabela 2: Teores de mercúrio $(\mu \mathrm{g} / \mathrm{L})$ em águas sanitárias comercializadas no Estado de São Paulo*

Mínimo Máximo Mediana $\begin{gathered}\text { Nonagésimo } \\ \text { percentil }\end{gathered}$

\begin{tabular}{rrrr}
\hline 5 & 146 & 15 & 67 \\
\hline Número
\end{tabular}

* Número de amostras analisadas: 69

Pelas concentrações de mercúrio encontradas nas águas sanitárias analisadas, foi verificado que se usando as quantidades de hipoclorito recomendadas pelas autoridades sanitárias ${ }^{4}$ para descontaminar hortaliças e frutas (uma colher de sopa, $15 \mathrm{~mL}$, para cada litro de água) e água (duas gotas por litro de água), o mercúrio residual não apresenta riscos à saúde, já que a quantidade ingerida é menor do que os limites máximos recomendados pelas legislações em vigor ${ }^{2,3}$ que estabelecem, respectivamente para água e alimentos, $0,001 \mathrm{mg} / \mathrm{L}$ e $0,01 \mu \mathrm{g} / \mathrm{kg}$. Considerando o valor máximo de mercúrio encontrado nas amostras $(116 \mu \mathrm{g} / \mathrm{L})$ e conforme diluição recomendada para água potável, o teor de mercúrio residual é de $0,01 \mu \mathrm{g} / \mathrm{L}$.

Para a determinação de mercúrio em água sanitária por espectrofotometria de absorção atômica há necessidade de se eliminar o cloro pois se observa uma interferência espectral. Neste caso, foram testadas soluções de ácido nítrico e ácido clorídrico. Foi observado que o $\mathrm{HCl}$ é mais eficiente e rápido que o $\mathrm{HNO}_{3}$, pois facilita a formação e eliminação de cloro $\mathrm{cm}$ função da seguinte reação de oxi-redução:

$$
\mathrm{ClO}^{-}+2 \mathrm{II}^{+}+\mathrm{Cl}^{-} \rightleftharpoons \mathrm{Cl}_{2}+\mathrm{H}_{2} \mathrm{O}
$$

Além disso, a utilização do IINO3 apresenta o inconveniente da formação de NO2 que também absorve no comprimento de onda do IIg, causando uma interferência espectral que leva a resultados maiores que os esperados.

O mercúrio a baixas concentrações é facilmente absorvido pelas paredes dos frascos usados para a preparação da amostra . A utilização do ácido clorídrico minimiza este tipo de perda devido à formação de complexos de cloro com o mercúrio ( $\mathrm{HgCl}_{3}^{-}$e $\left.\mathrm{IgCl}_{4}^{2-}\right)^{10}$, o que justifica a utilização do ácido cloridrico ao invés do ácido nítrico.

P'clo método de adição de padrão verificouse que a matriz da água sanitária tratada não apresenta problemas de interferências, e padrões aquosos poderão ser usados para cálculo da concentração.

O limite de determinação do método é de $5 \mathrm{mg} / \mathrm{L}$. 
O método proposto para determinação de mercúrio apresentou um desvio-padrão de $\pm 2,5$ $\mu \mathrm{g} / \mathrm{L}$ e um C.V. de $6,4 \%$ para uma amostra com teor de $\mathrm{Hg}$ de $40 \mu \mathrm{g} / \mathrm{L}$.

\section{Conclusões}

O método proposto para tratamento de amostras de água sanitária é simples, rápiclo e eficiente, não apresentando perdas do mercúrio por volatilização.

As amostras de águas sanitárias, quando usadas na desinfecção de frutas, hortaliças e água, nas diluições recomendadas pelas autoridades sanitárias, não apresentam riscos à saúde com relação ao teor de mercúrio residual.

ZENEBON, O. et al. [Determination of mercury content in bleaches sold in southeastern Brazil]. Rev. Saúde Pública, 28: 127 - 30, 1994. In order to determine the mercury content present as a contaminant in samples of bleach used in water and food disinfection, a method for sample treatment using chloridric acid to eliminate the chlorine was proposed. The technique of cold vapour atomic absorption spectrophotometry, used to quantify the mercury, showed a recovery of $103 \%$. Sixty nine samples of bleach were analysed and the values found for the median and $90^{\mathrm{th}}$ percentil were respectively, 15 and $67 \mu \mathrm{g} / \mathrm{L}$. According to the values of residual mercury found and using the quantities of bleach recommended by the Brazilian Sanitary Authorities, the use of these disinfectants offers no risk to human health.

Keywords: Mercury, analysis. Spectrophotometry, atomic absorption. Disinfectants, analysis.

\section{Referências Bibliográficas}

1. ANALYTICAL METIIODS COMMITTEE. The determination of snatl amounts of mercury in organic matter. Analyst, 90: 515-530, 1265.

2. BRASIL, Leis, etc. Resolução n ${ }^{\circ} 18 / 75$ do Ministério da Saúde. Diário Oficial da União, Brasilia, 9 dez. 1975 , Sec. I. p. 16378.

3. BRASIL, Leis, etc. Portaria $n^{2} 36 / 90$ do Ministério da Saúde. Diário Oficial da União, Brasilia, 23 jan. $1990, \operatorname{Sec} I$, p. 1651-3.

4. BRASIL, Leis, etc. Comunicado CVS - 1/91 da Secretaria de Estado da Saúde. Diário Oficial do Estado de São Paulo, São Paulo, 11 maio 1991, Scc I. p. 17-8

5. BRASIL, Leis, etc. Portaria $n^{\circ} 134 / 92$ do Ministério da Saúde. Diário Oficial da União, Brasília, 28 set. 1992, Sec. I, p. 13512.

6. DYCIIDALA, G.R. Chlorine and chlorine compounds. In: Block, S.S., ed. Disinfection, sterilization and preservation. $2^{\text {nd }} \mathrm{cd}$. Philadelphia, Lea \& Fibiger, 1977. p. 189.

7. ILATCII, W.R. \& OTT, W.L. Determination of sub-microgram quantities of mercury by atomic absorption spectrophotometry. Anal. Chem., 40: 2085-7, 1968.

8. LARINI, L. Toxicologia. Sĩo Paulo, Manole, 1987.

9. LAU, O.; IION, P.; CIIEUNG, C.; CIIAU, M. Determination of mercury in chinese medicinal pills by cold vapour atomic absorption spectrometry. Analyst, 110: $483-5,1985$.

10. LOUIE,II.W.; GO,D.; IEDCZINA, M.; JUDO, K.; DALINS, J. Digestion of food samples for total mercury determination.J. Ass. Off. Anal. Chem., 68: 891-3, 1985.

Recebido para publicação em 12.7.1993 Reapresentado em 28.12.1993

Aprovado para publicação em 31.1.1994 